\title{
Fatores socioculturais e nível de atividade física no início da adolescência
}

\author{
Helen Gonçalves, ${ }^{1}$ Pedro C. Hallal, ${ }^{1,2}$ Tales C. Amorim, ${ }^{2}$ \\ Cora L. P. Araújo e Ana M. B. Menezes ${ }^{1}$
}

Como citar Gonçalves H, Hallal PC, Amorim TC, Araújo CLP, Menezes AMB. Fatores socioculturais e nível de atividade física no início da adolescência. Rev Panam Salud Publica. 2007;22(4):246-53.

RESUMO Objetivo. Descrever o nível de atividade física de adolescentes nascidos em 1993 em Pelotas (Brasil) e avaliar o efeito de variáveis socioculturais sobre o nível de atividade física.

Métodos. Utilizamos uma combinação de duas abordagens metodológicas, a epidemiológica e a etnográfica. No estudo epidemiológico, 4452 adolescentes nascidos em 1993 foram entrevistados. O nível de atividade física foi avaliado através de questionário. Foram classificados como sedentários os adolescentes com menos de 300 minutos por semana de atividade física. $O$ estudo etnográfico incluiu 69 adolescentes, selecionados aleatoriamente entre todos os participantes da coorte. Foram realizadas, em média, três entrevistas aprofundadas (uma a cada 6 meses), separadamente com as mães e os adolescentes.

Resultados. A prevalência de sedentarismo foi de 48,7\% (IC95\%: 46,5 a 50,8) nos meninos e 67,5\% (IC95\%: 65,6 a 69,5) nas meninas ( $\mathrm{P}<0,001$ ). A variável independente que apresentou a associação mais forte com o nível de atividade física foi o número de vezes por semana que o adolescente encontrava amigos fora do ambiente escolar. O estudo etnográfico mostrou que os meninos têm mais apoio social e familiar para a realização de atividades físicas na adolescência e que muitos pais atribuem o mau desempenho escolar ao tempo gasto na rua.

Conclusões. Este estudo sugere que a atividade física é muitas vezes considerada como concorrente dos valores familiares na adolescência. É importante que essa noção seja foco de estudos adicionais e que seja trabalhada junto às famílias para que a atividade física possa ser adotada como um hábito cultural.

Palavras-chave Adolescente, atividade física, estilo de vida, Brasil.

Existem evidências de que os adolescentes ativos têm maior probabilidade de se tornar adultos ativos quando comparados com os adolescentes sedentários (1-8). No Brasil, há

\footnotetext{
Universidade Federal de Pelotas, Programa de Pós-Graduação em Epidemiologia. Enviar correspondência a Helen Gonçalves no seguinte endereço: Centro de Pesquisas Epidemiológicas, Marechal Deodoro $1160,3^{\circ}$ piso, CEP 96020-220, Pelotas, RS, Brasil. Fone/fax: +55-53-3284.1324; e-mail: hdgs@uol.com.br

2 Universidade Federal de Pelotas, Programa de PósGraduação em Educação Física, Pelotas (RS), Brasil.
}

um interesse crescente na promoção de estilos de vida ativos, que podem auxiliar no combate à epidemia de sobrepeso observada no País. Nesse contexto, o Ministério da Saúde e grupos locais têm conduzido iniciativas com o intuito de mobilizar a população (9, 10).

Apesar do reconhecimento da importância da atividade física para a saúde, ainda existem poucos estudos de base populacional sobre o tema no Brasil, especialmente incluindo ado- lescentes (11-13). A maior parte dos estudos existentes avalia o efeito de fatores demográficos, socioeconômicos e biológicos sobre a ocorrência de sedentarismo, sendo que pouca atenção foi dada aos fatores socioculturais. Contudo, recentes estudos de revisão têm enfatizado a importância de tais fatores na determinação do estilo de vida dos indivíduos $(14,15)$.

O objetivo do presente artigo foi descrever os níveis de atividade física de adolescentes nascidos em 1993 na 
Cidade de Pelotas (Brasil) e avaliar, através de uma combinação das metodologias epidemiológica e etnográfica, o efeito de determinadas variáveis socioculturais sobre o nível de atividade física. Uma descrição inicial do nível de atividade física desses adolescentes foi publicada recentemente (16), sem pretender, no entanto, explorar o efeito das variáveis socioculturais.

\section{MÉTODOS}

\section{Componente epidemiológico}

No ano de 1993, 5265 bebês nasceram vivos na Cidade de Pelotas, Brasil. Quase todas as mães ( $n=5249)$ concordaram em participar de um estudo longitudinal sobre a saúde de seus filhos. As mães foram entrevistadas após o parto; entrevistadores treinados aplicaram um questionário padronizado e pré-testado (17) que abordou fatores demográficos, socioeconômicos, comportamentais e de saúde. Posteriormente, amostras dessas crianças foram visitadas em várias ocasiões durante a infância, mas nenhuma dessas visitas buscou localizar todos os participantes da coorte (17).

Em 2004 e 2005, decidiu-se entrevistar todos os participantes da coorte de 1993. Os adolescentes foram procurados a partir de diversas estratégias de busca, sendo as principais um censo de todos os domicílios do Município e um censo das 99 escolas locais. Todas as mortes de membros da coorte ocorridas entre 1993 e 2005 foram identificadas através do Sistema de Informação de Mortalidade (SIM). Maiores detalhes sobre a metodologia do estudo de coorte de 1993 estão disponíveis em outra publicação (17).

O trabalho de campo dessa segunda fase foi iniciado em julho de 2004 e encerrado em março de 2005. Entrevistadores treinados aplicaram três instrumentos durante visitas domiciliares, sendo que cada visita durava, em média, 45 minutos. Os supervisores do trabalho de campo repetiram $10 \%$ das entrevistas como forma de controle de qualidade; não foram detectadas falhas graves no trabalho dos entrevista- dores em relação ao contato com as famílias, ao preenchimento do questionário ou às medidas antropométricas. Os dados foram duplamente digitados no programa Epi Info 6.04b. A limpeza e a análise de dados foram realizadas no pacote estatístico Stata 8.0.

Nessa visita de 2004 e 2005, três questionários foram aplicados. O questionário materno buscou informações de contato para auxiliar na localização futura dos participantes da coorte e contemplou variáveis relacionadas à composição familiar, escolaridade do adolescente, indicadores socioeconômicos (segundo critérios da Associação Brasileira de Empresas de Pesquisa, ABEP) (18), variáveis socioculturais, saúde familiar e comportamento dos pais.

Os outros dois questionários foram respondidos diretamente pelo adolescente participante da coorte. O primeiro foi aplicado através de entrevista, abrangendo questões sobre escolaridade, atividade física, padrões de dieta, trabalho e variáveis socioculturais. O segundo foi autopreenchido sem auxílio materno e incluiu questões sobre tabagismo, consumo de álcool, participação em brigas, relacionamento com os pais e saúde mental. A confidencialidade foi garantida.

Tendo em vista que a prática de atividade física no lazer é apenas um subgrupo da atividade física total, optamos por utilizar dois indicadores de sedentarismo: o sedentarismo no lazer, que engloba a prática de esportes, ginástica ou dança no tempo livre, e o sedentarismo total, que engloba o modo de deslocamento para a escola e a prática (ou não) de atividades físicas estruturadas ou não estruturadas, na escola ou em outros espaços. O sedentarismo foi definido como menos de 300 minutos por semana de atividades físicas de intensidade moderada à vigorosa, de acordo com as recomendações atuais para adolescentes (19).

Após análises descritivas, a prevalência de sedentarismo foi calculada para cada subgrupo das variáveis independentes. Testes do qui-quadrado $\left(\chi^{2}\right)$ para heterogeneidade ou tendência linear foram aplicados para avaliar a significância estatística das asso- ciações. Para obter um ajuste adequado para o efeito do nível socioeconômico (que tem se mostrado um importante fator de confusão em estudos sobre comportamento de adolescentes), três variáveis foram usadas como potenciais fatores de confusão nos modelos de regressão: renda familiar ao nascer, escolaridade materna em 1993 e índice de bens atual. A análise multivariável foi conduzida por meio de regressão de Poisson, recomendada para desfechos binários com alta prevalência (20).

O estudo foi aprovado pelo Comitê de Ética em Pesquisa da Faculdade de Medicina da Universidade Federal de Pelotas. Consentimentos por escrito para a realização da entrevista foram solicitados aos pais ou responsáveis pelos adolescentes.

\section{Componente etnográfico}

Em 1993, um estudo etnográfico foi conduzido com 80 mães de participantes da coorte, aproximadamente 1 mês após o nascimento das crianças. Tais mães são representativas da coorte como um todo, tendo sido selecionadas de forma aleatória (21). O objetivo inicial do estudo etnográfico, em 1993, foi analisar como as mães tomavam decisões sobre a utilização de serviços de saúde e a saúde/doença de seus filhos. Em 2004 e 2005, decidimos revisitar as mesmas mães para analisar as trajetórias de vida dessas famílias e suas repercussões na saúde dos filhos. Após a localização das famílias, foram conduzidas entrevistas aprofundadas separadamente com as mães e os adolescentes por uma equipe de três entrevistadoras com treinamento na área. Ao longo de 1 ano, foram realizadas, em média, três entrevistas por família, com revisitas a cada 6 meses. Todas as entrevistas foram gravadas, com consentimento da família e do jovem, e transcritas pela equipe. A etnografia realizada nos permitiu analisar algumas das razões que levam certos adolescentes a serem fisicamente ativos e outros não. As seguintes estratégias metodológicas foram utilizadas no estudo etnográfico: história de vida, observação estruturada e 
semi-estruturada e conversas informais. Os adolescentes incluídos no estudo etnográfico serão revisitados a cada 4 meses até 2008, quando uma nova visita a todos os participantes da coorte será realizada.

Das 80 mães entrevistadas em 1993, 86\% foram localizadas em 2004 e 2005. A principal razão para as 11 perdas foi a mudança de cidade. Nesta análise, os seguintes aspectos do estudo etnográfico foram priorizados: atividades de lazer, prática esportiva e diferenças entre meninos e meninas. A opinião das mães sobre a socialização dos adolescentes também foi analisada.

\section{RESULTADOS}

\section{Componente epidemiológico}

Dos 5249 participantes da coorte, 4452 foram entrevistados em 2004 e 2005. Considerando ainda os 141 óbitos da coorte detectados no SIM, obteve-se uma taxa de acompanhamento de $87,5 \%$. Os jovens localizados são semelhantes aos perdidos em termos de sexo, nível socioeconômico e antropometria ao nascer (16).

A prevalência encontrada de sedentarismo total foi de 48,7\% (IC95\%: 46,5 a 50,8 ) nos meninos e $67,5 \%$ (IC95\%: $65,6$ a 69,5$)$ nas meninas $(P<0,001)$. Considerando-se apenas a atividade física de lazer, os valores foram de 59,0\% (IC95\%: 56,6 a 60,8) para os meninos e 77,7\% (IC95\%: 76,5 a 80,0) para as meninas $(P<0,001)$.

A tabela 1 apresenta a prevalência de sedentarismo total e no lazer em meninos e meninas, separadamente, conforme as variáveis independentes do estudo (extraídas dos três questionários). A prevalência de sedentarismo total nos meninos foi maior nos seguintes grupos: filhos de mães mais velhas, nível socioeconômico alto, filhos de mães que não trabalham fora de casa, jovens criados muito "presos" pela mãe, jovens que segundo a mãe nunca tiveram "más companhias", jovens que não trabalhavam e não participavam das tarefas domésticas, jovens brancos ou indígenas e que não encontravam amigos com freqüência.
Nas meninas, o nível socioeconômico alto, a ausência de "más companhias", a não participação em atividades domésticas, o medo de morar na vizinhança, a baixa freqüência de encontro com amigas e a pele negra associaramse com maior percentual de sedentarismo no total. Já o sedentarismo no lazer associou-se, nos meninos, com a ausência de trabalho materno, criação muito "presa", ausência de trabalho fora de casa, não participação em tarefas domésticas, baixa freqüência de encontro com amigos e pele branca ou ser indígena. Nas meninas, o sedentarismo no lazer foi estatisticamente mais freqüente nos seguintes grupos: meninas que não participavam em tarefas domésticas, meninas que tinham medo de morar na vizinhança e meninas que raramente ou nunca encontram amigos fora dos horários de aula. A figura 1 destaca a associação entre o sedentarismo e o número de vezes por semana que o adolescente encontrava os amigos fora de casa. $O$ ajuste por indicadores socioeconômicos (dados não apresentados) removeu o efeito das seguintes variáveis sobre a prevalência de sedentarismo: trabalho materno e medo de morar na vizinhança.

\section{Componente etnográfico}

A adolescência compreende várias etapas, abrindo possibilidades para que os jovens se sintam e se coloquem de forma menos infantilizada diante de seus pares e familiares (22). A idade é um definidor cultural importante, assim como o desenvolvimento do corpo para os enfoques biomédico e estético (aceitação social). Ser mais velho e ter mais idade faz com que os jovens encontrem razões para requerer novos limites e inserções sociais. No componente qualitativo deste estudo, pode-se ver claramente tal argumentação como justificativa para atividades de recreação.

Quando chegam aos 10 ou 12 anos, os adolescentes sentem que as exigências em relação a praticar esportes e a brincar são diferentes. Exige-se mais "seriedade", e, para atender a essas expectativas, uma estratégia é comu- mente usada: evitar ao máximo o uso do verbo brincar nas conversas com os pares e familiares. Tal atitude faz com que os adolescentes se sintam mais seguros, mais fortes, mais adultos e menos crianças. Futebol, boneca, vôlei, andar de bicicleta e skate passam de brincadeiras a coisas que se faz. Brincar é muito diferente de jogar.

Por exemplo, muitas meninas negavam inicialmente que "ainda brincavam" de boneca. Para elas não existe um equivalente ao futebol, praticado mais pelos meninos. Futebol não tem idade, enquanto que brincar de boneca, segundo os adolescentes, é "coisa de criança"-quando elas brincavam, o faziam em locais fechados e exclusivamente com as amigas íntimas. No entanto, de modo contraditório, em alguns momentos, muitas delas ainda usaram o verbo brincar para falar de jogos, diferentemente dos meninos, que preferiam dizer que jogavam bola, jogavam futebol, andavam de bicicleta. A conotação e a prática mais infantil presentes no brincar são evitadas para quem quer se mostrar mais crescido. As meninas tendiam a não brincar e a jogar pouco, visto que, no espaço da rua, elas deviam ter mais cuidados que os meninos.

Uma quantidade considerável da atividade física dos meninos desta amostra ocorria fora das escolas e academias, sendo realizada no bairro, no deslocamento para a casa dos amigos, no trajeto casa-escola e em outros percursos feitos a pé ou de bicicleta. Os meninos tinham claramente mais liberdade de ir e vir do que as meninas. Também tinham aprendido a negociar os seus conhecimentos com as famílias de tal modo que, comparados às meninas, se deslocavam para locais mais distantes do domicílio. As meninas passavam por um processo semelhante de negociação, mas as suas chances de sucesso eram menores. Geralmente, elas recebiam autorização para deslocamentos maiores quando estavam acompanhadas de amigas, visto que, nesse caso, alguns perigos da rua poderiam ser minimizados.

Os cuidados com a moral feminina eram mais explícitos e faziam com que os responsáveis procurassem cuidar 
TABELA 1. Prevalência de sedentarismo em meninos e meninas nascidos em 1993 conforme variáveis independentes, Pelotas (RS), Brasil, 2004 e 2005a

\begin{tabular}{|c|c|c|c|c|c|c|c|c|}
\hline \multirow[b]{4}{*}{ Variável } & \multicolumn{8}{|c|}{ Sedentarismo $0^{b}$} \\
\hline & \multicolumn{4}{|c|}{ Total } & \multicolumn{4}{|c|}{ Lazer } \\
\hline & \multicolumn{2}{|c|}{ Meninos } & \multicolumn{2}{|c|}{ Meninas } & \multicolumn{2}{|c|}{ Meninos } & \multicolumn{2}{|c|}{ Meninas } \\
\hline & $\%$ & $P$ & $\%$ & $P$ & $\%$ & $P$ & $\%$ & $P$ \\
\hline Idade materna (anos) & & 0,02 & & 0,28 & & 0,37 & & 0,87 \\
\hline$<30$ & 43,6 & & 68,0 & & 56,6 & & 81,9 & \\
\hline 30 a 34 & 48,0 & & 64,3 & & 58,4 & & 76,9 & \\
\hline 35 a 39 & 46,0 & & 68,3 & & 57,8 & & 77,5 & \\
\hline 40 a 49 & 52,0 & & 68,7 & & 60,0 & & 77,9 & \\
\hline$\geq 50$ & 53,7 & & 68,9 & & 60,0 & & 82,0 & \\
\hline \multicolumn{9}{|l|}{ Classificação econômica } \\
\hline da família ${ }^{c}$ & & 0,02 & & 0,005 & & 0,10 & & 0,41 \\
\hline A (mais rico) & 58,8 & & 69,3 & & 60,0 & & 69,3 & \\
\hline $\mathrm{B}$ & 53,2 & & 75,3 & & 60,3 & & 78,9 & \\
\hline $\mathrm{C}$ & 46,8 & & 68,1 & & 56,7 & & 77,1 & \\
\hline $\mathrm{D}$ & 49,2 & & 64,4 & & 61,4 & & 78,4 & \\
\hline $\mathrm{E}$ (mais pobre) & 40,1 & & 61,2 & & 51,0 & & 79,6 & \\
\hline Trabalho materno & & 0,03 & & 0,74 & & 0,008 & & 0,09 \\
\hline Não & 51,2 & & 67,3 & & 61,9 & & 80,0 & \\
\hline Sim & 46,4 & & 68,0 & & 56,1 & & 76,9 & \\
\hline \multicolumn{9}{|l|}{ Tipo de criação dado } \\
\hline pela mãe & & 0,001 & & 0,13 & & $<0,001$ & & 0,06 \\
\hline Mais livre & 41,3 & & 66,1 & & 49,4 & & 76,3 & \\
\hline Mais preso & 51,2 & & 68,6 & & 61,6 & & 79,4 & \\
\hline Igual & 42,7 & & 63,0 & & 52,7 & & 73,7 & \\
\hline Anda com más companhias & & 0,008 & & 0,003 & & 0,07 & & 0,08 \\
\hline Não & 51,6 & & 70,1 & & 60,7 & & 79,5 & \\
\hline $\operatorname{Sim}$ & 45,8 & & 64,0 & & 56,8 & & 76,4 & \\
\hline Jovem trabalha fora & & $<0,001$ & & 0,62 & & $<0,001$ & & 0,24 \\
\hline Não & 49,6 & & 67,6 & & 59,6 & & 78,5 & \\
\hline $\operatorname{Sim}$ & 31,9 & & 64,7 & & 42,9 & & 72,5 & \\
\hline \multicolumn{9}{|l|}{ Jovem ajuda nas tarefas } \\
\hline domésticas & & $<0,001$ & & $<0,001$ & & $<0,001$ & & $<0,001$ \\
\hline Não & 53,7 & & 74,5 & & 63,5 & & 83,4 & \\
\hline $\operatorname{Sim}$ & 43,8 & & 64,9 & & 53,9 & & 76,3 & \\
\hline \multicolumn{9}{|l|}{ Jovem tem medo de morar } \\
\hline na vizinhança & & 0,60 & & 0,002 & & 0,29 & & 0,02 \\
\hline Não & 48,8 & & 69,0 & & 59,0 & & 79,2 & \\
\hline $\operatorname{Sim}$ & 47,1 & & 60,7 & & 55,7 & & 73,9 & \\
\hline \multicolumn{9}{|l|}{ Dias por semana encontrando } \\
\hline amigos & & $<0,001$ & & $<0,001$ & & $<0,001$ & & $<0,001$ \\
\hline 0 & 65,5 & & 76,1 & & 76,6 & & 85,9 & \\
\hline 1 e 2 & 54,4 & & 71,7 & & 64,9 & & 80,8 & \\
\hline 3 e 5 & 47,1 & & 61,4 & & 57,4 & & 76,1 & \\
\hline $6 \mathrm{ou}+$ & 38,6 & & 58,4 & & 47,6 & & 69,6 & \\
\hline Cor da pele do jovem & & $<0,001$ & & 0,001 & & 0,02 & & 0,25 \\
\hline Branca & 51,4 & & 70,5 & & 60,7 & & 79,4 & \\
\hline Negra & 40,4 & & 79,2 & & 52,3 & & 73,3 & \\
\hline Mulata & 43,3 & & 63,2 & & 53,1 & & 77,7 & \\
\hline Amarela & 32,6 & & 60,4 & & 53,5 & & 75,0 & \\
\hline Indígena & 54,7 & & 61,8 & & 64,2 & & 78,2 & \\
\hline
\end{tabular}

a Número de meninos: 2 181; número de meninas: 2259.

b Os valores de $P$ foram calculados pelo teste do qui-quadrado $\left(\chi^{2}\right)$.

c Critério de Classificação Econômica Brasil (18). 
FIGURA 1. Prevalência de sedentarismo conforme o número de dias por semana que o adolescente encontra os amigos, Pelotas (RS), Brasil, 2004 e 2005

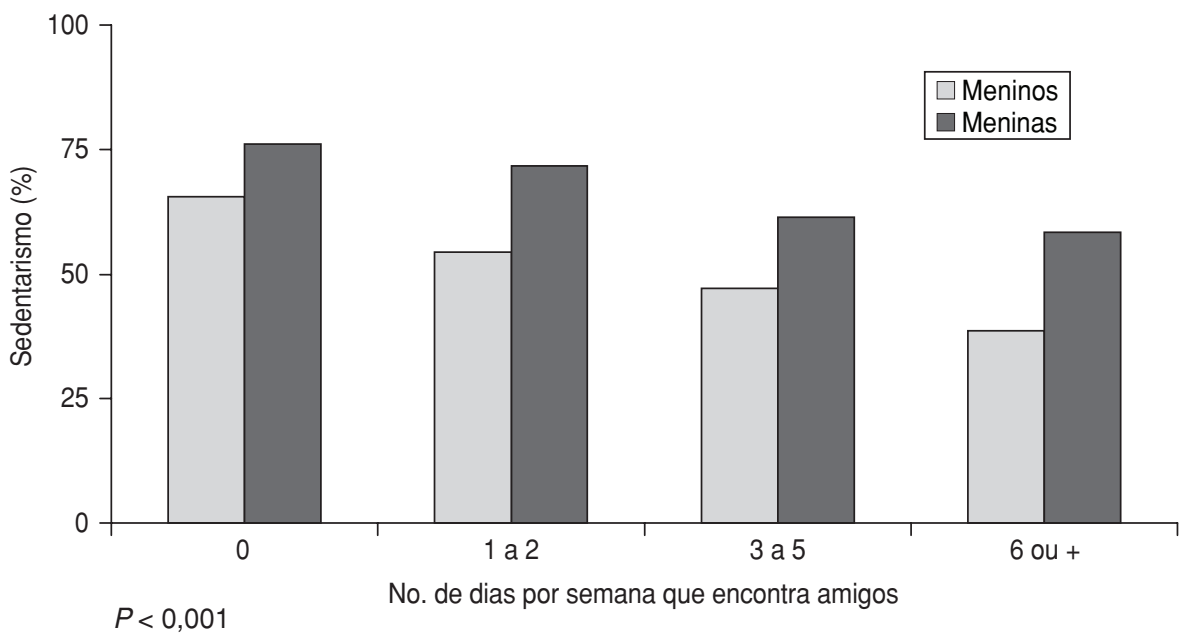

das meninas de modo diferente, reduzindo as possibilidades de elas "andarem" na rua. Assim sendo, nesse contexto de preocupações com a rede social, as questões de gênero ficaram bastante visíveis. Por exemplo, $15 \%$ das mães relataram que sua maior preocupação com a adolescência dos filhos era o namoro/sexo. Dessas, apenas $2,6 \%$ eram mães de meninos. As meninas também tinham horários mais restritos do que os meninos - a população da rua muda nos diferentes períodos do dia e, assim, mudavam os limites delas e deles. No caso das meninas, as observações etnográficas mostraram que elas se deslocavam caminhando e conversando- o que também é um indicador de "adolescência". Para elas, "adolescentes" conversam e andam mais calmamente do que as "crianças" que brincam na rua.

Além disso, as jovens consideravam os meninos nessa idade "mais estúpidos/brutos" em seus jogos e acreditavam que eles preferiam competir com elas do que interagir coletivamente- - a rua passava a ser deles e das "crianças". Elas passavam a vê-los como mais imaturos/infantis do que elas próprias. Além disso, o caminhar por lazer com uma ou mais amigas no bairro, no centro ou nas redondezas da casa assumia o caráter de "paquera" (namoro), algo bem menos próximo do brincar/jogar. Nota-se a pouca interação existente entre os meninos e as meninas no que se refere ao brincar ou à própria prática de atividade física. Os comportamentos esperados pelos pares e, por vezes, pelos próprios familiares, colocavam barreiras às aproximações que não eram motivadas pelo namoro ou pelo simples confronto de forças entre os dois sexos.

A imposição das mães para que as meninas se restringissem ao espaço da casa ou da vizinhança reflete a rua como um espaço mais masculino. Casa e rua são duas categorias sociológicas bastante trabalhadas no Brasil (23). Entre o espaço da casa e da rua há toda a representatividade de um "espaço moral". A moral e os bons costumes, por exemplo, estariam mais associados ao espaço da casa, ao espaço íntimo e privado, de aprendizado da educação. A rua representaria o oposto, o local de movimento, de fluidez e de burlar regras. Esse antagonismo estaria presente na forma como as famílias articulam o que os filhos podem (e quando podem) fazer na rua e em casa, e com que idade.

Frente a esse constante jogo de permissão e limitação dos pais e das novas experiências dos jovens quanto ao que a rua/casa representa, não é de admirar que $76 \%$ dos responsáveis nesta coorte tenham expressado a sua preocupação com a qualidade das amizades dos filhos e afirmado que os criavam "mais presos". Além disso, $73 \%$ mencionaram incômodo com a chegada da adolescência. A aparente contradição entre criar preso e ter amigos ruins se dissolve quando se entende que há, ao mesmo tempo, nesse período, uma diminuição dos controles parentais e um estímulo familiar para a autonomia juvenil (ainda com limites), permitindo um alargamento da rede social dos jovens (na escola, bairros próximos). Portanto, essa é uma etapa em que os pais se mostram mais preocupados com os amigos que não conhecem bem, que não moram no bairro, ou que moram, mas agora interagem com seus filhos comumente na rua-onde os adolescentes querem passar mais tempo.

Durante o trabalho de observações e entrevistas, notamos que algumas meninas ganharam, com o decorrer do tempo, a permissão para ir mais longe, à medida que precisavam se deslocar para a escola, que tinham mais compromissos e que se mostravam confiáveis para os pais (cumpridoras de suas tarefas). Junto com a permissão, elas ouviam dos pais que deviam tomar cuidado ao andar na rua. A prática diária/semanal de percorrer algum trajeto só ou acompanhada fazia com que as meninas mais ativas estivessem mais atentas às possibilidades de perigo dentro e fora do seu bairro, e que conseguissem detectar com mais sensibilidade as ameaças ou sentir mais medo. Isso reforça as evidências de que o tipo de atividade/esporte a ser incitado ou circunscrito, tanto no lazer quanto nas instituições, está sujeito ao papel de gênero e aos estereótipos e acontecimentos da vida urbana e da adolescência.

A associação mais forte encontrada para os jovens de ambos os sexos nas análises epidemiológicas deste trabalho foi entre atividade física e encontrar os amigos. Este dado permite referendar a importância da rede social no sentido de aumentar a possibilidade e a probabilidade de ser mais ativo fisicamente, e o componente etnográfico nos permitiu compreender melhor esses resultados. Quanto mais amigos - dependendo do tipo de amigomenor era o medo das mães de deixar os adolescentes saírem de casa para jogar ou conversar. O bairro, nesse con- 
texto, funciona como um grande observador/protetor; vizinhos, pais ou parentes podem exercer um certo controle sobre os eventos preocupantes. Ser conhecido dá, de certo modo, mais liberdade de estar com outros jovens e jogar e andar (a pé ou de bicicleta).

Outro fator importante para o entendimento do sedentarismo, nessa fase de vida, foi investigado através da constatação de que, ao contrário dos meninos, as meninas mencionavam ter iniciado distintas atividades físicas, como dança de diferentes tipos (realizada em instituições fechadas). Porém eram elas também as que permaneciam por menos tempo nesses cursos, mudando ou abandonando a atividade. Durante as interações com os jovens e familiares, os dois motivos colocados como preponderantes para o abandono dos cursos incluíram: menos tempo para os estudos e necessidade de ajudar em casa. Se o estudo não ia bem e as jovens faziam alguma atividade física, esta era eliminada, como demonstra a fala de Taís (pseudônimo):

Taís: Eu saí da dança

Entrevistador: Por que, não podia ficar?

Taís: Podia, mas a minha mãe me tirou, para mim me encarnar (dedicar) mais. Porque eu não queria caderno!

Além disso, essas atividades são normalmente ofertadas fora do horário de aula, expondo as meninas a andar sozinhas em horários indesejáveis para os pais. A ajuda em casa, como outro motivo, foi geralmente alegada pelos responsáveis quando a filha não fazia as suas atividades domésticas com certo capricho ou diariamente. Assim como no caso do fracasso escolar, a punição para quem não colaborava em casa era menos liberdade para sair e, conseqüentemente, menos prática de atividade física no lazer.

Penalizar com a imposição de dificuldades para a prática de atividades físicas também foi um recurso usado contra os meninos, como demonstra Felipe (pseudônimo):

Felipe: Comecei a chorar muito, fiquei com medo que minha mãe fosse me bater (havia reprovado na $5^{a}$ série)
Entrevistador: Que a tua mãe fosse te bater?

Felipe: $E^{\prime}$

Entrevistador: E aí, tu rodou por quê?

Felipe: Era porque eu brincava muito.

No entanto, os dados do componente epidemiológico mostraram resultados diferentes: 37,4\% dos adolescentes já haviam sido reprovados na escola até 2004 e 2005. Quando se comparam o sedentarismo e o desempenho escolar, os mais ativos rodaram menos $(P<0,001)$, o que não está de acordo com o argumento dos pais de que a atividade física atrapalhava o desempenho escolar. A escola tem uma função de socialização considerável e, nesse momento da vida, uma importância lúdica fundamental. Alguns pais ou responsáveis que não acompanhavam o desempenho escolar dos filhos se surpreenderam com os resultados baixos e usaram como punição a proibição do encontro com os amigos, o que, por conseqüência, pode ter significado não praticar esporte ou outras atividades de lazer. Agindo dessa maneira, os pais acreditavam estar revertendo uma situação em prol dos estudos e contra a "liberdade".

\section{DISCUSSÃO}

Os dados existentes sobre atividades físicas, incluindo as realizadas nos momentos de lazer, têm contribuído para a identificação de subgrupos populacionais com maior freqüência de sedentarismo. Os achados sobre sedentarismo total e no lazer podem guiar estratégias efetivas que visem a aumentar o nível de atividade física na população. Optamos por estudar separadamente o sedentarismo total e o sedentarismo no lazer porque os estudos com adultos têm mostrado que existem fatores diferentes associados a cada um desses desfechos (24). Por exemplo, no Brasil, a caminhada no lazer é mais comum entre os ricos, enquanto o deslocamento a pé para o trabalho é mais comum entre os pobres (24). Conciliar abordagens metodológicas enriquece as análises e colabora para o entendimento de fatores que afetam, positiva ou negativamente, o nível de atividade física dos indivíduos, muitos dos quais podem estar bastante relacionados a componentes sociais, históricos e culturais.

Como a prática de atividade física é um comportamento complexo, determinado por inúmeros fatores, é importante diferenciar as razões que levam meninos e meninas a optarem por estilos de vida ativos ou sedentários. É importante lembrar que não são só os aspectos biológicos que tornam os meninos e as meninas diferentes; existem vários passos no processo de criação da subjetividade que também são distintos, dependendo do gênero. Em cada sociedade, questões de classe social e gênero configuram relações específicas que determinam as possibilidades ou impossibilidades de cada adolescente. É imperativo que se considerem as questões de gênero para que se entenda mais detalhadamente o processo de socialização de cada sujeito. É no convívio diário com a família, os amigos, os vizinhos, os professores, a mídia e outros que o adolescente aprende e compreende o que é socialmente aceito, quais atividades se espera que ele realize, quais tipos de interações com outros adolescente são necessárias e onde ele pode ir, entre outros aspectos relativos à sua socialização.

Vários estudos sobre atividades físicas em adolescentes mostram que os meninos são mais ativos do que as meninas (25). Na idade escolar, um estudo mostrou que a diferença entre os gêneros variou de 15 a 25\% (26). É um desafio constante decodificar as questões de gênero com a intenção de relacioná-las com a prática de atividades físicas. Essa dificuldade se dá não somente por envolver subjetividades, mas também pelo fato de co-existirem diversos outros aspectos culturais que não podem ser desconsiderados. Dessa forma, relacionar gênero com os espaços e tempos percorridos pelos jovens ao longo de sua vida permite que o conhecimento sobre comportamento seja aprofundado e se torne uma ferramenta fundamental para ações futuras cujo objetivo é promover um estilo de vida mais saudável entre os adolescen- 
tes. As transformações sociais, econômicas e culturais impõem constantemente uma série de mudanças comportamentais que interferem na decisão de praticar uma atividade física e desenvolver outros hábitos saudáveis, assim como de mantê-los por um longo tempo. A família, como espaço e agente privilegiado de socialização, adota e recria referenciais que permitem aos jovens adquirir elementos identitários e reconhecer os limites e os deveres de cada componente. Essa educação para a socialização comporta, evidentemente, o sistema de gênero, que ratifica operações de classificação, oposição, qualificação e hierarquização desde a infância.

$O$ gênero é um elemento constitutivo das relações sociais baseadas nas distinções percebidas entre os sexos (27). Historicamente, a socialização de moças e rapazes se diferenciou. Por exemplo, desde o século XIX até meados do século XX, a educação feminina direcionou-se basicamente ao lar e ao casamento. Meninas com 13 ou 14 anos de idade não deveriam tardar em casar, visto que a puberdade era notada primeiramente nelas do que nos meninos (28). Tais aspectos ainda podem afetar a educação dos jovens, podendo ajudar a explicar o menor nível de atividade física das meninas em comparação aos meninos.

Porém, os aspectos econômicos e situacionais que caracterizam o local de moradia também são relevantes. Temse proposto que o ambiente pode exercer um forte efeito sobre o nível de atividade física dos indivíduos (29). Entre os adolescentes no presente estudo, a vizinhança é um fator importante a ser considerado. De acordo com o local onde moram, os adolescentes podem ser mais ou menos ativos fisicamente. Isso se explica pela possibilidade de andar livremente nas ruas sem preocupação com a violência urbana ou por um sentimento de insegurança e vulnerabilidade que pode levar a um grau de isolamento social e a diferentes modos de socialização que não incluam a atividade física com outros jovens. Esse efeito, no entanto, foi observado somente entre as meninas, $\mathrm{e}$ apenas na análise bruta.

As concepções socioculturais precisam ser absorvidas para que ganhem significado para a prática da atividade física. As atividades de meninos e meninas se distinguem à medida que a auto-imagem de adolescente (em crescimento) vai sendo introjetada. Considerando esse aspecto, é possível compreender como a associação entre ser mais ativo e ter amigos vistos pelos pais como "má companhia" tem um significado sociocultural. Os dados epidemiológicos instigaram o olhar para entender o que é uma "má companhia" e o que a adolescência provoca em termos de alargamento dos limites de deslocamento e da diminuição do controle sobre as atividades dos jovens. A associação entre ser mais ativo e ter amigos que são "más companhias" pode ser explicada pelo fato de as mães, geralmente, considerarem como "más companhias" os jovens que passam muito tempo fora de casa, brincando, jogando, correndo ou mesmo fumando, ou seja, realizando várias atividades de socialização na rua que incluem atividades tanto físicas quanto de ruptura com a imagem de criança. Embora a discussão deste artigo não compreenda toda a complexidade do contexto local e cultural, ela colabora para levantar novas pistas analíticas. No caso das "más companhias", por exemplo, não faria sentido incorporar tal achado diretamente na agenda das recomendações das organizações responsáveis por políticas de saúde nesta área. Tal achado só faz sentido se contextualizado e repensado em termos de orientações aos pais.

Outro ponto a ser salientado é a idéia de estilo de vida e atividade física. Estilo de vida engloba um conjunto de escolhas comportamentais (familiares e individuais) que reproduzem condições de existência e necessidades sentidas como importantes. As prioridades juvenis/adolescentes, nesse sentido, serão norteadas por escolhas e conhecimentos pessoais e parentais, de acordo com as percepções acerca do que é saúde, adolescência, ser pai ou mãe e de como é ou deve ser o filho, entre outras. Essas concepções podem ou não estimular os adolescentes para a realização de atividades físicas. Por exemplo, pode-se interpretar que a atividade física (deslocamento, trabalho, lazer, escola) concorre com os valores familiares na adolescência em muitos aspectos e em diferentes níveis, como no caso da relação estabelecida entre o fracasso escolar o e tempo gasto com brincadeiras. A justaposição dos fatores culturais e históricos apontados (idade/ adolescência, valores sociais/ gênero) ressalta a ligação existente entre os determinantes sociais e os desfechos em saúde. Diante dos resultados, torna-se um pouco mais clara a existência de relações importantes entre o sedentarismo, a adolescência e aspectos nem sempre mensuráveis da vida social.

Tendo em vista a escassez de estudos que combinem as metodologias epidemiológica e etnográfica, especialmente na área da atividade física, e a riqueza de informações que essa combinação pode trazer, sugere-se que outros pesquisadores aprofundem os aspectos discutidos neste artigo, avaliando também a aplicabilidade de nossos achados a outras populações.

\section{REFERENCIAS}

1. Azevedo MR, Araújo CL, Silva MC, Hallal PC. Tracking of physical activity from adolescence to adulthood: a populationbased study. Rev Saude Publica. 2007; 41(1):69-75.
2. Alfano CM, Klesges RC, Murray DM, Beech BM, McClanahan BS. History of sport participation in relation to obesity and related health behaviors in women. Prev Med. 2002; 34(1):82-9.
3. Beunen GP, Lefevre J, Philippaerts RM, Delvaux K, Thomis M, Claessens AL, et al. Adolescent correlates of adult physical activity: a 26-year follow-up. Med Sci Sports Exerc. 2004;36(11):1930-6. 
4. Boreham C, Robson PJ, Gallagher AM, Cran GW, Savage JM, Murray LJ. Tracking of physical activity, fitness, body composition and diet from adolescence to young adulthood: The Young Hearts Project, Northern Ireland. Int J Behav Nutr Phys Act. 2004;1:14.

5. De Bourdeaudhuij I, Sallis J, Vandelanotte C. Tracking and explanation of physical activity in young adults over a 7-year period. Res Q Exerc Sport. 2002;73(4):376-85.

6. Gordon-Larsen P, Nelson MC, Popkin BM. Longitudinal physical activity and sedentary behavior trends: adolescence to adulthood. Am J Prev Med. 2004;27(4): 277-83.

7. Kraut A, Melamed S, Gofer D, Froom P. Effect of school age sports on leisure time physical activity in adults: The CORDIS study. Med Sci Sports Exerc. 2003;35(12): 2038-42.

8. Tammelin T, Nayha S, Hills AP, Jarvelin MR. Adolescent participation in sports and adult physical activity. Am J Prev Med. 2003;24(1): 22-8.

9. Matsudo SM, Matsudo VR, Araújo TL, Andrade DR, Andrade EL, de Oliveira LC, et al. The Agita Sao Paulo Program as a model for using physical activity to promote health. Rev Panam Salud Publica. 2003;14(4):265-72.

10. Brasil, Ministério da Saúde. Política Nacional de Promoção da Saúde [site na Internet]. Disponível em: http://portal. saude.gov.br/ portal/saude/visualizar_texto.cfm?idtxt=23 615\&janela $=1$. Acessado em 5 de março de 2007.

11. Oehlschlaeger MH, Pinheiro RT, Horta B, Gelatti C, San'Tana P. Prevalence of sedentarism and its associated factors among urban adolescents. Rev Saude Publica. 2004;38(2): 157-63.

12. Silva RCR, Malina RM. Nível de atividade física em adolescentes do Município de Nite- rói, Rio de Janeiro, Brasil. Cad Saude Publica. 2000;16(4):1091-7.

13. Hallal PC, Wells JC, Reichert FF, Anselmi L, Victora CG. Early determinants of physical activity in adolescence: prospective birth cohort study. BMJ. 2006;332(7548): 1002-7.

14. Trost SG, Owen N, Bauman AE, Sallis JF, Brown W. Correlates of adults' participation in physical activity: review and update. Med Sci Sports Exerc. 2002;34(12): 1996-2001.

15. Bauman AE, Sallis JS, Dzewaltowski DA, Owen N. Toward a better understanding of the influences on physical activity: the role of determinants, correlates, causal variables, mediators, moderators, and confounders. Am J Prev Med. 2002;23(2 Suppl):5-14.

16. Hallal PC, Bertoldi AD, Gonçalves H, Victora CG. Prevalence of sedentary lifestyle and associated factors in adolescents aged 10 to 12 years. Cad Saude Publica. 2006;22(6):1277-87.

17. Victora CG, Araujo CL, Menezes AM, Hallal PC, Vieira MF, Neutzling MB, et al. Methodological aspects of the 1993 Pelotas (Brazil) Birth Cohort Study. Rev Saude Publica. 2006;40(1):39-46.

18. Associação Brasileira de Empresas de Pesquisa. Critério de classificação econômica Brasil [site da Internet]. São Paulo: ABEP; 2007. Disponível em: http://www.abep. org/default.aspx?usaritem=arquivos\&iditem $=23$. Acessado em set-embro de 2007.

19. Biddle S, Cavill N, Sallis J. Young and active? Young people and health-enhancing physical activity - evidence and implications. Londres: Health Education Authority; 1998.

20. Barros AJ, Hirakata VN. Alternatives for logistic regression in cross-sectional studies: an empirical comparison of models that directly estimate the prevalence ratio. BMC Med Res Methodol. 2003;3:21
21. Behague DP, Victora CG, Barros FC. Consumer demand for cesarean sections in Brazil: informed decision making, patient choice, or social inequality? A population based birth cohort study linking ethnographic an epidemiological methods. BMJ. 2002;324(7343): 942-5.

22. Magro V. Adolescentes como autores de si próprios: cotidiano, educação e o hip hop. Cad CEDES. 2002;22(57):63-75.

23. DaMatta R. A casa e a rua. Rio de Janeiro: Rocco; 1981.

24. Hallal PC, Azevedo MR, Reichert FF, Siqueira FV, Araujo CL, Victora CG. Who, when, and how much? Epidemiology of walking in a middle-income country. Am J Prev Med. 2005;28(2):156-61.

25. Farias Jr. J, Lopes A. Comportamentos de risco relacionados à saúde em adolescentes. Rev Bras Cien Mov. 2004;12(1):7-12.

26. Sallis J. Epidemiology of physical activity and fitness in children and adolescents. Crit Rev Food Sci Nutr. 1993;33(4-5):403-8.

27. Scott J. Gênero: uma categoria útil de análise histórica. Rev Educ Soc. 1990;16(2):5-22.

28. Thierce A. Histoire de l'adolescence (18501914). Paris: Belin; 1999

29. Dowda M, Ainsworth BE, Addy CL, Saunders R, Riner W. Environmental influences, physical activity, and weight status in 8- to 16-year-olds. Arch Pediatr Adolesc Med. 2001;155(6):711-7.

Manuscrito recebido em 9 de março de 2007. Aceito em versão revisada em 4 de julho de 2007
ABSTRACT

Sociocultural factors and physical activity level in early adolescence

Key words Adolescent, physical fitness, exercise, life style, Brazil.
Objective. To describe the level of physical activity in adolescents born in 1993 in the city of Pelotas, Brazil, and to evaluate the effect of sociocultural variables on those levels.

Methods. A combined ethno-epidemiological methodology was employed. In the epidemiological study, 4452 adolescents born in 1993 were interviewed. Physical activity level was evaluated by means of a questionnaire. Adolescents with fewer than 300 minutes of physical activity per week were classified as sedentary. The ethnographic study included 69 adolescents randomly selected from among all cohort participants. On average, three in-depth interviews were carried out (about one every 6 months), with mothers and adolescents being interviewed separately.

Results. The prevalence of a sedentary lifestyle was $48.7 \%$ (95\%CI: 46.5 to 50.8 ) in boys and $67.5 \%$ (95\%CI: 65.6 to 69.5$)$ in girls $(\mathrm{P}<0.001)$. The independent variable presenting the strongest association with physical activity level was the weekly frequency with which the adolescent met friends outside of school. The ethnographic study showed that boys have more social and family support to engage in physical activities in adolescence, but that many parents associate poor school performance with the amount of time spent outside the home.

Conclusions. This study suggests that physical activity is often viewed as competing with family values in adolescence. This perspective should be explored in future studies and discussed with families so that physical activity may be adopted as a cultural norm. 